\title{
Pancreatic Neuroendocrine Tumor by AJCC v8 Stage
}

National Cancer Institute

\section{Source}

National Cancer Institute. Pancreatic Neuroendocrine Tumor by AJCC v8 Stage. NCI

Thesaurus. Code C135560.

A term that refers to the staging of a pancreatic neuroendocrine tumor, following the rules of the TNM AJCC V8 classification system. This staging system applies to welldifferentiated neuroendocrine tumors arising in the pancreas. Carcinomas of the pancreas, including high-grade (grade 3), poorly differentiated neuroendocrine carcinomas are not staged using this staging system. (from AJCC 8th Ed.) 